\title{
The Vibration of Tubular Beam Conveying Fluid with Variable Cross Section
}

\author{
Mohamed Gaith* \\ ${ }^{1}$ Department of Mechanical Engineering, Al-Balqa Applied University, 11171 Amman, P. O. B. 710709, Jordan \\ *Corresponding author, e-mail: mohamedgaith@bau.edu.jo
}

Received: 20 August 2020, Accepted: 05 October 2020, Published online: 09 December 2020

\begin{abstract}
The dynamics and stability of flow induced vibration of flow conveying in pipes particularly in case of high velocity flow may lead to severe damage. Predicting the circular natural frequencies and critical fluid velocities is an important tool in design and prevent system failures. In this study transverse dynamic response of simply supported pipe with variable tubular cross sectional area carrying fluid with a constant flow rate is investigated. Euler Bernoulli's beam theory is used to model the pipe. Hamilton's principle will be used to produce the governing equation of motion for the system. The resulting partial differential equation is solved using Galerkin's technique. The impact of the flow velocity and non-uniform variable cross section on the natural frequencies of the system, critical flow velocity and system stability is presented.
\end{abstract}

Keywords

fluid structure interaction, conveying pipe, natural frequencies, critical velocity, stability, variable cross section

\section{Introduction}

Tubular beams conveying fluid are found in many engineering applications like aircraft engines, jet pumps, heat exchanger, nuclear reactors and human circulation. The flow-induced vibrations in such systems are known as fluid structure interaction. This brought huge attention on the dynamics ad stability of flow induced vibration of fluid conveying in pipes particularly in case of high velocity flow which may lead to severe damage [1-20]. Predicting the natural frequencies and critical flow velocities is an important tool in design and prevent system failures. There are a number of papers reporting the vibration of pipe conveying fluid. These include experiments and theoretical studies on the dynamic response of pipes with different boundary conditions such as simply supported pipes, cantilevered pipes, and curved pipes. Other engineering applications may require non-uniform cross section beams and pipes as it has better capacity and vibration characteristics in many applications. In most of these studies, the non-uniform beam is divided into several intact non-uniform beams in order to examine its natural vibration. As an application in biomechanics, from clinical practice, it is known that the blood flow in the arterial system is essential in the human body.
In early studies on flow induced vibration in pipes conveying fluid, Ashley and Haviland [1] attempted to study the vibration of the Trans-Arabian pipeline using Euler Bernoulli theory. Later on, Feodos'ev [2] and Housner [3], considered the Coriolis force in developing the governing equation of motion for simply supported conditions. They presented the natural frequencies and instability by bucking at critical velocities. Niordson [4] studied the problem of finding using shell theory and obtained similar results. Eigenvalues were presented analytically by Handelman [5]. Movchan [6] used Liapunov's direct method to analyze system's stability. Naguleswaran et al. [21] by theoretical and experimental study concluded that buckling may occur at small range of velocities for simply supported pipe conveying fluid. Thurman and Mote [22] used perturbation technique to investigate effect of nonlinearity in such systems, and found that nonlinearity increases the natural frequencies. Païdoussis and Issid [23], Paidoussis and Laithier [24] and Païdoussis et al. [25] showed the response of the natural frequencies and stability for different boundary conditions using Euler Bernoulli's and Timoshenk's beam theories. Nemat-Nasser et al. [26] presented the impact of velocity 
on the stability of conveying flow through tubular cantilevers. Using thin-shell theory, Weaver and Unny [27] found an interesting phenomenon that the simply supported pipes are not only subject to beam mode instability in terms of buckling, but also could be subject to coupled mode instability. Similar behavior was confirmed for clamped system by Païdoussis and Denise [28]. A comprehensive review of fluid-structure interaction of conveying flow in pipes is available by Ibrahim [20]. Gupta [29] studied the vibration tapered beam using finite element approach. Alshorbagy et al. [30] used virtual work approach to investigate the response of FG non-uniform beam. Caruntu [31] considered the nonlinear dynamics for non-uniform beams and developed the solution by utilizing the factorization method. Askarian et al. [32] analyzed the stability of thin variable cross-section beam conveying fluid using extended Hamilton's principle and the Galerkin method. Zhao et al. [33] used Chebyshev polynomial theory to analyze the vibration of functionally graded non-uniform beam considering both Euler-Bernoulli and Timoshenko beam theories. Very few studied considered the vibration of pipes conveying fluid with non-uniform cross section in biomechanics, aerospace and industrial applications. The variable cross section of the pipe conveying fluid is not thoroughly investigated. In which the application of such system can be found in nozzles, vehicles, and most of the arteries in the human body. For instance, the artery was assumed as a straight pipe with non-uniform cross section with external thick-walled tube and conveying fluid. Its dynamics and stability was investigated to obtain the effect of blood flow profile and variation of geometry on critical velocities and buckling [34], Hosseini and Paparisabet [35].

In this study transverse dynamic response of simply supported pipe with variable cross sectional area carrying fluid with a constant flow rate is investigated. Euler Bernoulli's beam theory is used to model the pipe. Hamilton's principle will be utilized to produce the governing equation of motion for the system. The resulting partial differential equation is solved using Galerkin's method. The impact of the flow velocity on the natural frequencies of the system and its stability is examined.

\section{Formulation of the problem}

The system considered constitutes a pipe of finite span L and mass per unit length $m(x)$ conveying a fluid with constant flow rate and inlet velocity $v_{o}$ and of mass per unit length $M(x)$. The pipe is of variable circular cross section and simply supported at ends, $E$ is Young's constant, $I(x)$ is variable inertia, and the pipe assumed to be inextensible.

Consider the pipe conveying fluid in the axial coordinate, $\mathrm{x}$-direction, and the transverse motion in the y-direction as in Fig. 1.

The equation of motion (Eq. (1)) for the simply supported pipe is developed based on kinetic, $T$, and potential, $V$, energies of the system:

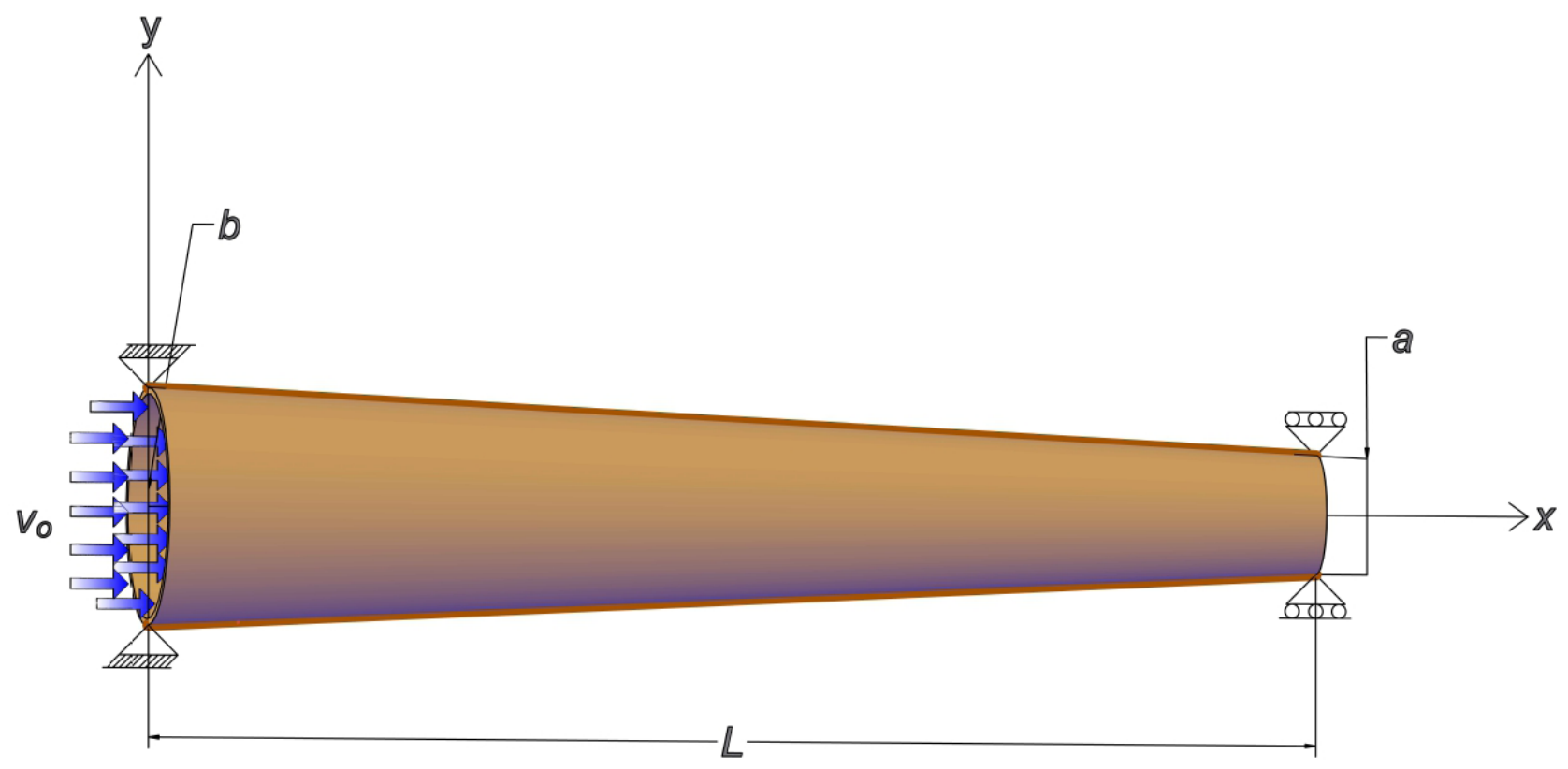

Fig. 1 Schematic diagram of simply supported pipe with non-uniform cross section. 


$$
\begin{aligned}
& T=T_{p}+T_{f} \\
& =\frac{1}{2} \int_{t_{1}}^{t_{t_{1}}}\left\{\begin{array}{l}
m\left(\frac{\partial w}{\partial t}\right)^{2}+M V^{2}+M\left(\frac{\partial w}{\partial t}\right)^{2} \\
+2 M V \frac{\partial w}{\partial t} \frac{\partial w}{\partial x}+M V^{2}\left(\frac{\partial w}{\partial x}\right) \mathrm{d} x
\end{array}\right\},
\end{aligned}
$$

$V=\frac{E}{2} \int_{0}^{L} I\left(\frac{\partial^{2} w}{\partial x^{2}}\right)^{2} \mathrm{~d} x$.

Introducing the Hamilton's principle:

$$
\delta \int_{t_{1}}^{t_{2}}(T-V) \mathrm{d} t=0
$$

Both $T$ and $V$ energies are derived for the model, followed by the variational procedure for the simply supported ends and using similar approach as Benjamin's [36], the governing differential equation of motion is derived in Eq. (4):

$$
\begin{aligned}
& E I \frac{\partial^{4} w}{\partial x^{4}}+\left(2 E \frac{\mathrm{d} I}{\mathrm{~d} x}\right) \frac{\partial^{3} w}{\partial x^{3}}+\left(E \frac{\mathrm{d}^{2} I}{\mathrm{~d} x^{2}}+M V^{2}\right) \frac{\partial^{2} w}{\partial x^{2}} \\
& +2 M V \frac{\partial^{2} w}{\partial x \partial t}+(M+m) \frac{\partial^{2} w}{\partial t^{2}} \\
& +M V \frac{\mathrm{d} V}{\mathrm{~d} x} \frac{\partial w}{\partial x}=0,
\end{aligned}
$$

where

$$
\begin{aligned}
& I(x)=\frac{\pi}{4}\left\{\begin{array}{l}
\left(a+(b-a) \frac{x}{L}+h\right)^{4} \\
-\left(a+(b-a) \frac{x}{L}\right)^{4}
\end{array}\right\} . \\
& V(x)=v_{o} \frac{b^{2}}{\left(a+(b-a) \frac{x}{L}\right)^{2}},
\end{aligned}
$$

where $w(x, t)$ is the transverse deflection of the pipe, $I(x)$, $V(x)$ are the moment of inertia and fluid velocity function at any location of the pipe, respectively, and $\mathrm{h}$ is the thickness of the circular pipe, with simply supported conditions:

$$
\begin{aligned}
& w=\frac{\partial^{2} w}{\partial^{2} x}=0 \quad \text { at } \quad x=0 \\
& w=\frac{\partial^{2} w}{\partial x^{2}}=0 \quad \text { at } \quad x=L
\end{aligned}
$$

Designating the non-dimensional parameters as:

$$
\begin{aligned}
& W=\frac{w}{L}, X=\frac{x}{L}, \bar{b}=\frac{b}{a}, \\
& T=\frac{t}{L^{2}}\left(\frac{E I}{M+m}\right)^{\frac{1}{2}}, \\
& \bar{h}=\frac{h}{a}, \omega=\left(\frac{M+m}{E I}\right)^{\frac{1}{2}} L^{2} \Omega,
\end{aligned}
$$

and letting:

$$
\begin{aligned}
& \beta=\frac{1}{1+\beta^{*}\left(\frac{2 \bar{h}}{1+(\bar{b}-1) X}\right)}, \\
& U=\left(\frac{\rho_{f} \pi}{E}\right)^{\frac{1}{2}} \frac{L v_{o}}{a^{2}}, \\
& A_{1}=\frac{\bar{b}^{2}}{(1+(\bar{b}-1) X)^{1}}, \\
& A_{2}=\frac{-2 \bar{b}^{-4}(\bar{b}-1)}{(1+(\bar{b}-1) X)^{3}}, \\
& A_{3}=\frac{\bar{b}^{4}}{(1+(\bar{b}-1) X)^{2}}, \\
& \bar{I}=\frac{\pi}{4}\left\{\begin{array}{l}
(1+(\bar{b}-1) X+\bar{h})^{4} \\
-(1+(\bar{b}-1) X)^{4}
\end{array}\right\},
\end{aligned}
$$

where $\beta^{*}=\frac{\rho_{p}}{\rho_{f}}$, and $\rho_{p}$, and $\rho_{f}$ are density of pipe and fluid, respectively, and $\Omega$ is the complex circular frequency. Hence, the governing equation is rendered as:

$$
\begin{aligned}
& \frac{\partial^{4} W}{\partial X^{4}}+\frac{2}{\bar{I}} \frac{\mathrm{d} \bar{I}}{\mathrm{~d} X} \frac{\partial^{3} W}{\partial X^{3}} \\
& +\left(\frac{1}{\bar{I}} \frac{\mathrm{d}^{2} \bar{I}}{\mathrm{~d} X^{2}}+\frac{1}{\bar{I}} U^{2} A_{3}\right) \frac{\partial^{2} W}{\partial X^{2}}+\frac{\partial^{2} W}{\partial T^{2}} \\
& +2 \beta^{\frac{1}{2}} U A_{1}\left(\frac{1}{\bar{I}}\right)^{\frac{1}{2}} \frac{\partial^{2} W}{\partial X \partial T}+U^{2} A_{2}\left(\frac{1}{\bar{I}}\right) \frac{\partial W}{\partial X}=0 .
\end{aligned}
$$

Assuming the general displacement solution for Eq. (15) is in the form of Eq. (16):

$W(X, T)=\varphi(X) e^{i \omega T}$,

where $\omega$ is the dimensionless circular frequency and substituting Eq. (16) in Eq. (15) the results are:

$$
\begin{aligned}
& \frac{d^{4} \varphi}{\mathrm{d} X^{4}}+A \frac{d^{3} \varphi}{\mathrm{d} X^{3}}+B \frac{d^{2} \varphi}{\mathrm{d} X^{2}} \\
& +C \frac{\mathrm{d} \varphi}{\mathrm{d} X}+D \varphi=0,
\end{aligned}
$$

where

$$
\begin{aligned}
& A=\frac{8(\bar{b}-1)}{(1+(\bar{b}-1) X)}, \\
& B=\frac{12(\bar{b}-1)^{2}}{(1+(\bar{b}-1) X)^{2}}+U^{2} \frac{4 \bar{b}^{4}}{\pi(1+(\bar{b}-1) X)^{6}},
\end{aligned}
$$


$C=2 \beta^{\frac{1}{2}} U\left(\frac{(2) \bar{b}^{2}}{\sqrt{\pi}(1+(\bar{b}-1) X)^{3}}\right) i \omega$

$+U^{2} \frac{-8 \bar{b}^{4}(\bar{b}-1)}{\pi(1+(\bar{b}-1) X)^{7}}$,

$D=-\omega^{2}$.

Using the Galerkin's method with two terms of harmonic sine function:

$\varphi(X)=c_{1} \sin \pi X+c_{2} \sin 2 \pi X$,

and solving the system by making use of the support conditions. Eq. (7), the general complex frequencies of the system is determined in terms of $\beta^{*}$ and $U_{1}$.

\section{Results and discussion}

The significant parameters that affect the stability of the system from Eq. (15) are the ratio of pipe density to fluid density, $\beta^{*}$, the non-dimensional inlet velocity of the fluid, $U$, and the change of the circular cross section presented in terms of input to output radius ratio $b / a$, to be designated as the non-uniform cross section ratio, through the spatial coordinate $(X)$. In this paper, I have chosen a linear change in the radius of the circular cross section, say $r(x)$ through the spatial coordinate $x$, written as:

$r(x)=a+(b-a) \frac{x}{L}$.

To be confident from the derivations of the governing equations and results, we compared our results for the case of uniform cross section, $b / a=1.0$, as shown in Fig. 2, to the available results in the literature [36,37] of uniform cross section with the same configuration, and it was with excellent agreement. Fig. 2 shows the Argand diagram of complex components, i.e. real and imaginary, of the circular natural frequency in terms of inlet velocity, $U$. For pipe conveying a fluid with uniform cross section with simply

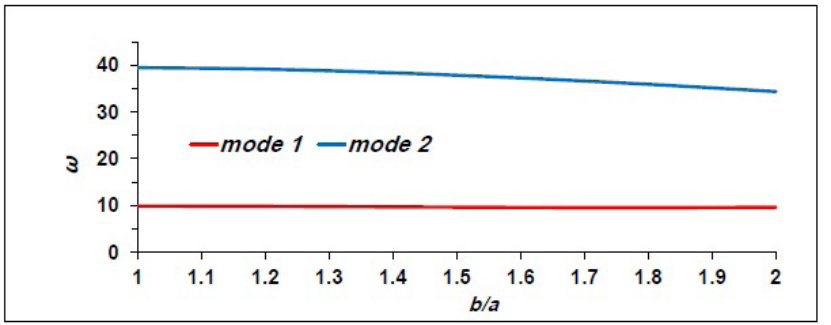

Fig. 2 The non-dimensional first two natural frequencies versus the nonuniform cross section ratios, $b / a$ for stationary fluid, $U=0$. supported ends, as the flow velocity increases, the first natural frequency gradually decrease until it vanishes at the first critical velocity, and becomes negative imaginary, leading to divergence instability. Upon increasing the flow velocity until the second natural frequency vanished at the second critical velocity, and becomes negative imaginary, with further increase in velocity till then an interesting phenomenon occurred where the first mode frequency amalgamates with the second mode frequency to generate coupled mode flutter [27].

In general, the pure imaginary part of the complex natural frequency will determine when the system undergoes unstable motion. If the imaginary part of $\omega$ is negative, it indicates that the system undergoes unstable motion. Meanwhile, if the imaginary part of $\omega$ is positive, the system undergoes stable (damping) motion. In our solutions of $\omega_{n}$, we present these values (natural frequencies) and explore the effect of $\beta^{*}, U$, and $b / a$.

In Fig. 3, the natural frequencies of the system are plotted with stationary fluid, $U=0$, for different $b / a$ ratios. Apparently, the first (lowest) natural frequencies are slightly decreased by increasing the b/a ratio, meanwhile significantly the second natural frequencies is decreased by increasing the $b / a$ ratio. The real and imaginary parts of non-dimensional first two natural frequencies in terms of inlet velocity, $U$, for simply support end with non-uniform cross section $(b / a=1.2)$ is presented in Fig. 4. For all $2.39>U>0$, first natural frequency has real and very small negative imaginary parts. The first critical velocity for the first natural frequency with $b / a=1.2$ is decreased down to $U_{c 1}=2.39$. For $4.7>U>2.39$, it has positive imaginary part indicating stable behavior in that rage. Then it goes with two different negative pure imaginaries till $U=5.0$ with unstable behavior, then it goes with real and negative imaginary parts till $U=6.4$ indicating oscillatory

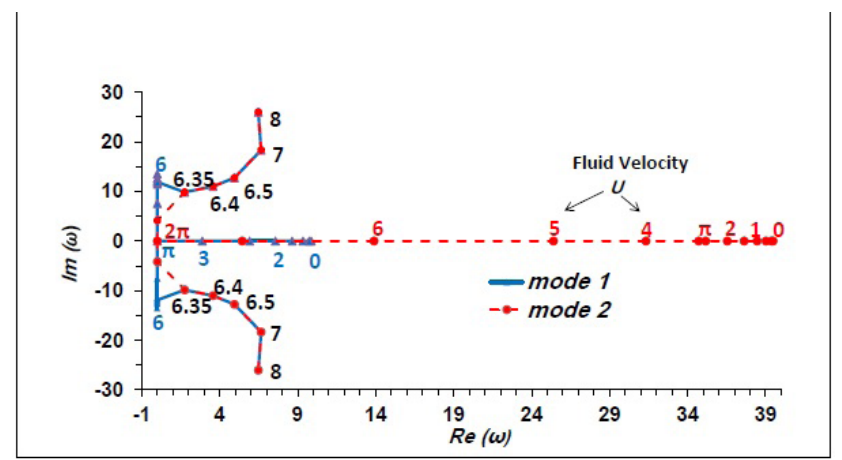

Fig. 3 The Argand diagram of the real and imaginary of non-dimensional natural frequencies in terms of non-dimensional velocity for simply support end with uniform cross section $(b / a=1.0)$. 


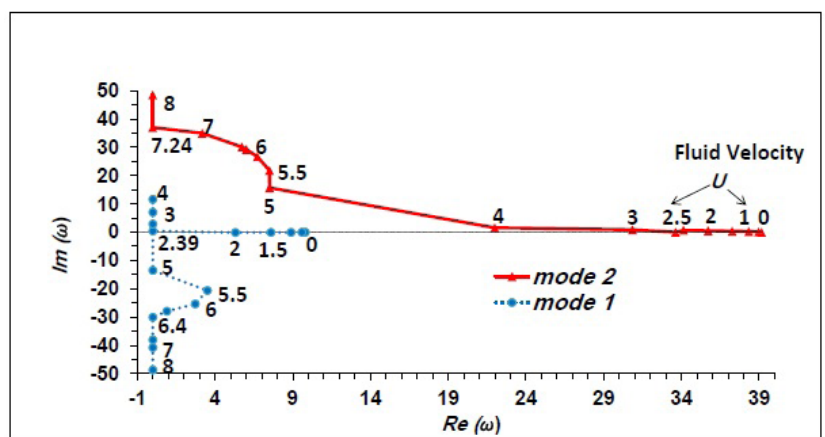

Fig. 4 The real and imaginary of non-dimensional first two natural frequencies in terms of non-dimensional velocity for simply support end with non-uniform cross section $(b / a=1.2)$.

divergence, then gain it goes with two different negative imaginary parts. Apparently the system shows unstable in the first frequency mode, except for $4.7>U>2.39$, as the imaginary part is always negative. For $U>0$, all the non-dimensional second natural frequencies are consisting of both real and imaginary parts. As the velocity increases the real part is decreasing till it vanishes at $U_{c 2}=7.24$ and at the same time the positive imaginary part is building up. At the second critical velocity, instability by divergence occurs. Upon increasing $U>7.24$, the natural frequency becomes positive pure imaginary indicating stability. For the case of non-uniform cross section ( $b / a=1.4)$, Fig. 5 shows the real and imaginary components of non-dimensional first two natural frequencies in terms of inlet velocity $(U)$ for simply support end. The first critical velocity for the first natural frequency with $b / a=1.4$ is decreased down to $U_{c 1}=1.901$, then it goes with pure negative imaginaries indicating instability. Similar behavior is found for $b / a=1.6,1.8$ and 2.0 with $U_{c 1}=1.59,1.38$ and 1.28 , respectively, as shown in Figs. 6 to 8 .

Figs. 5 to 8 also show the real and positive imaginary parts of non-dimensional second natural frequencies as

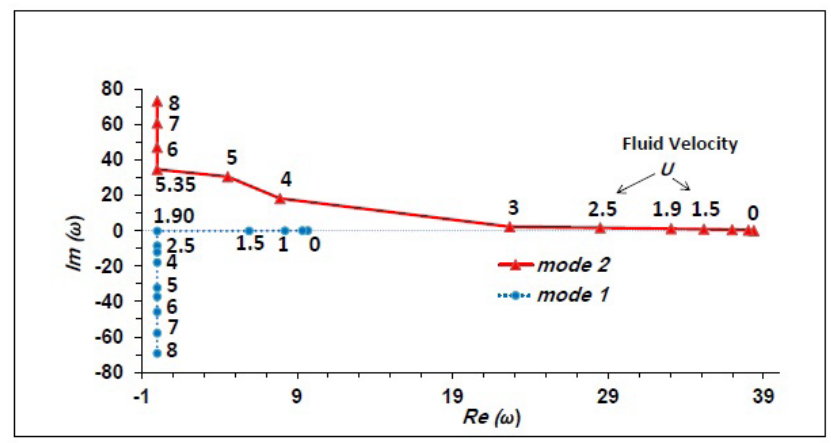

Fig. 5 The real and imaginary of non-dimensional first two natural frequencies in terms of non-dimensional velocity for simply support end with non-uniform cross section $(\mathrm{b} / \mathrm{a}=1.4)$

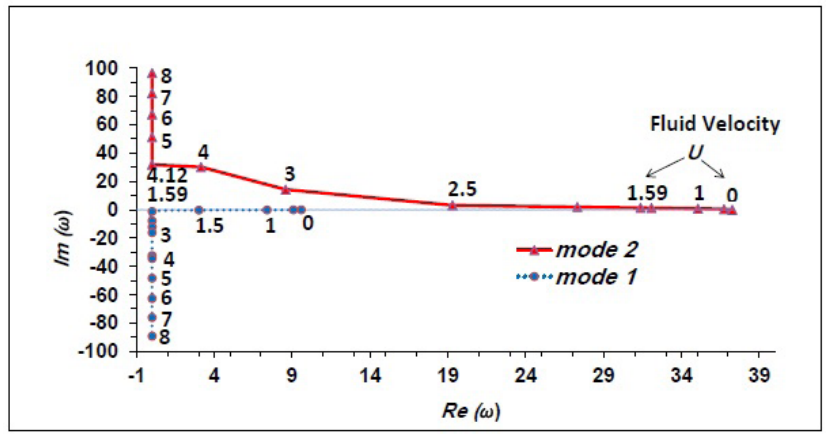

Fig. 6 The real and imaginary of non-dimensional first two natural frequencies in terms of non-dimensional velocity for simply support end with non-uniform cross section $(b / a=1.6)$.

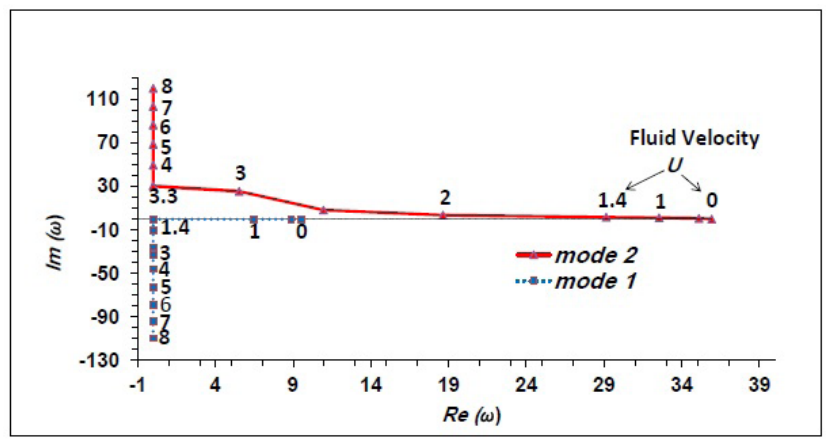

Fig. 7 The real and imaginary of non-dimensional first two natural frequencies in terms of non-dimensional velocity for simply support end with non-uniform cross section $(b / a=1.8)$.

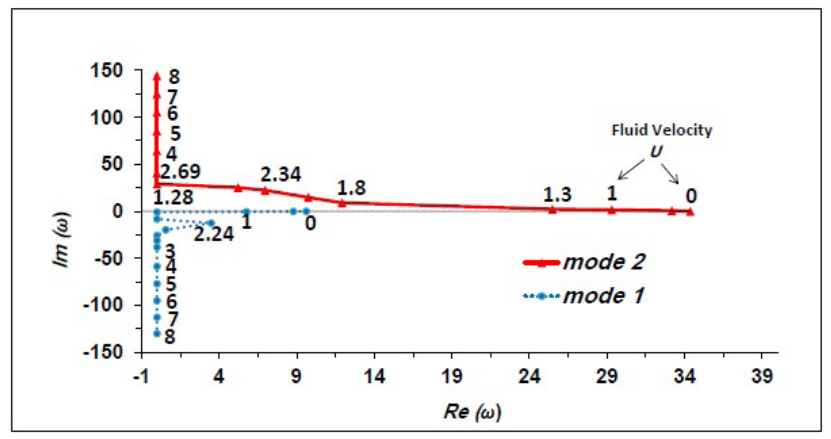

Fig. 8 The real and imaginary of non-dimensional first two natural frequencies in terms of non-dimensional velocity for simply support end with non-uniform cross section $(b / a=2.0)$.

a function of non-dimensional velocity for simply support end with non-uniform cross sections $(b / a=1.4$, 1.6, 1.8, and 2.0), respectively. Similar trend to $b / a=1.2$ can be found for $b / a=1.4,1.6,1.8$, and 2.0 with $U_{c 2}=5.35,4.12,3.29$ and 2.69 , respectively.

It can be concluded that this system configuration is stable in the second mode with reduced critical velocity. Fig. 9 presents the real part of the first natural frequencies with the inlet fluid velocity, $U$, for different non-uniform cross sections ( $b / a=1.0,1.2,1.4,1.6,1.8,2.0$ ). As the non-dimensional velocity increases, the real part of the first natural 


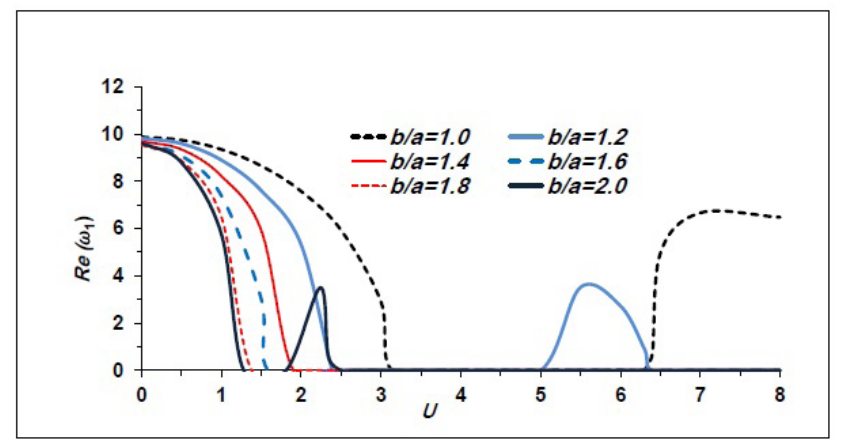

Fig. 9 The non-dimensional fluid velocity versus the real non-dimensional first natural frequencies for different non-uniform cross sections $(b / a=1.0,1.2,1.4,1.6,1.8,2.0)$.

frequency decreases. For the second first natural frequency, similar trend can be observed except for $b / a=1.2$ as shown in Fig. 10. Finally, from Fig. 11 we can conclude that the larger the non-uniform cross section ratio, the smaller the first critical velocity except for $b / a=1.2$ where it has unexpected increase in the critical velocity.

\section{Conclusion}

The dynamic response of simply supported variable cross section pipe conveying fluid is investigated, and the stability of the system is illustrated. Euler Bernoulli's beam theory is utilized to model the pipe. Hamilton's principle will be utilized to produce the governing equation of motion for the system. The resulting partial differential equation is solved using Galerkin's technique. The complex natural frequencies and critical flow velocities are calculated for different variable cross section ratios. The effect of

\section{References}

[1] Ashley, H., Haviland, G. "Bending Vibrations of a Pipe Line Containing Flowing Fluid", Journal of Applied Mechanics, 72, pp. 229-232, 1950.

[2] Feodos'ev, V. P. "Vibrations and stability of a pipe when liquid flows through it", Inshenerik Sbrnik, 10, pp. 169-170, 1951.

[3] Housner, G. W. "Bending Vibrations of a Pipe Line Containing Flowing Fluid", Journal of Applied Mechanics, 19(2), pp. 205-208, 1952.

[4] Niordson, F. I. "Vibrations of a cylindrical tube containing flowing fluid", Kungliga Tekniska Hogskolans Handlingar, Lindstahl, Stockholm, Sweden, 1953.

[5] Handelman, G. H. "A note on the transverse vibration of tube containing flowing fluid", Quarterly of Applied Mathematics, 13, pp. 326-330, 1955.

https://doi.org/10.1090/qam/74256

[6] Movchan, A. A. "On the problem of stability of a pipe with Fluid flowing through it", Journal of Applied Mathematics and Mechanics, 29(4), pp. 760-762, 1965.

https://doi.org/10.1016/0021-8928(65)90102-4

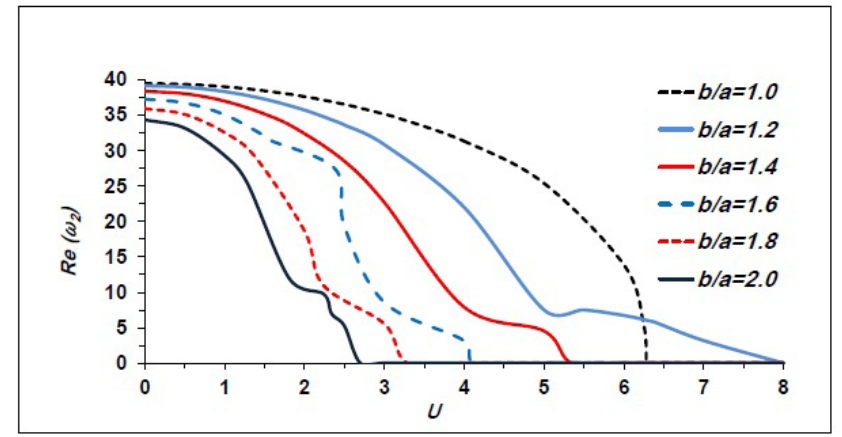

Fig. 10 The non-dimensional fluid velocity versus the real non-dimensional second natural frequencies for different non-uniform cross sections $(b / a=1.0,1.2,1.4,1.6,1.8,2.0)$.

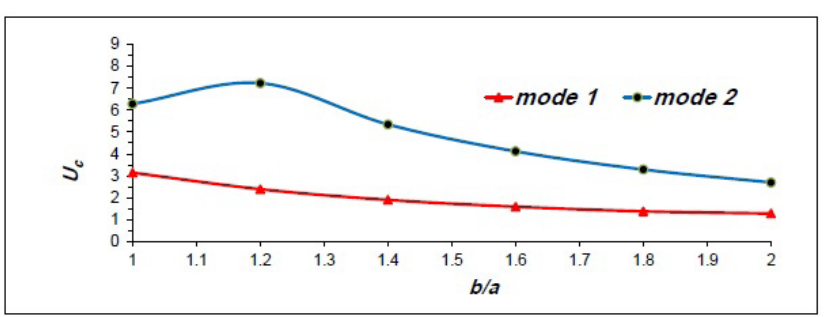

Fig. 11 The non-dimensional critical fluid velocity, $U_{c}$, versus the nonuniform cross section ratios, $b / a$.

the flow velocity that conveys through the pipe and the non-uniform variable cross sectional area on stability is presented. It can be concluded that this system with conveying flow configuration is damping in the second mode, meanwhile it is undamping for the first mode for non-uniform cross section. The critical flow velocity is decreasing by increasing the cross section ratio $b / a$.

[7] Mironov, M. A., Pyatakov, P. A., Andreev, A. A. "Forced flexural vibrations of a pipe with a liquid flow", Acoustic Physics, 56(5), pp. 739-747, 2010.

https://doi.org/10.1134/S1063771010050222

[8] Kutin, J., Bajsić, I. "Fluid-dynamic loading of pipes conveying fluid with a laminar mean-flow velocity profile", Journal of Fluids Structures, 50, pp. 171-183, 2014.

https://doi.org/10.1016/j.jfluidstructs.2014.05.014

[9] Stein, R. A., Tobriner, M. W. "Vibration of Pipes Containing Flowing Fluid", Journal of Applied Mechanics, 37(4), pp. 906-916, 1970. https://doi.org/10.1115/1.3408717

[10] Zhang, Y. L., Gorman, D. G., Reese, J. M. "Analysis of the vibration of pipes conveying fluid", Proceedings of the Institution of Mechanical Engineers, Part C: Journal of Mechanical Engineering Science, 213(8), pp. 849-859, 1999. https://doi.org/10.1243/0954406991522455

[11] Öz, H. R., Boyaci, H. "Transverse vibrations of tensioned pipes conveying fluid with time-dependent velocity", Journal of Sound and Vibration, 236(2), pp. 259-276, 2000. https://doi.org/10.1006/jsvi.2000.2985 
[12] Seo, Y. S., Jeong, W. B., Yoo, W. S., Jeong, H. K. "Frequency response analysis of cylindrical shells conveying fluid using finite element method", Journal of Mechanical Science and Technology, 19(2), pp. 625-633, 2005.

https://doi.org/10.1007/BF02916184

[13] Jweeg, M. J., Yousif, A. E., Ismail, M. R. "Experimental Estimation of Critical Buckling Velocities for Conservative Pipes Conveying Fluid", Al-Khwarijmi Engineering Journal, 7(4), pp. 17-26, 2011. [online] Available at: http://alkej.uobaghdad.edu.iq/index.php/ alkej/article/view/77 [Accessed: 19 August 2020]

[14] Long, R. H. "Experimental and theoretical study of transverse vibration of a tube containing flowing fluid", Journal of Applied Mechanics, 22(1), pp. 65-68, 1955

[15] Liu, L., Xuan, F. "Flow-Induced Vibration Analysis of Supported Pipes Conveying Pulsating Fluid Using Precise Integration Method", Mathematical Problems in Engineering, 2010, Article ID: 806475,2010 https://doi.org/10.1155/2010/806475

[16] Yang, X., Yang, T., Jin, J. "Dynamic stability of a beam-model viscoelastic pipe for conveying pulsative fluid", Acta Mechanica Solida Sinica, 20(4), pp. 350-356, 2007. https://doi.org/10.1007/s10338-007-0741-x

[17] Holmes, P. J. "Pipe Supported at Both Ends Cannot Flutter", Journal of Applied Mechanics, 45(3), pp. 619-622, 1978. https://doi.org/10.1115/1.3424371

[18] Lee, S. I., Chung, J. "New Non-linear Modelling for Vibration Analysis of a Straight Pipe Conveying Fluid", Journal of Sound and Vibration, 254(2), pp. 313-325, 2002. https://doi.org/10.1006/jsvi.2001.4097

[19] Vassilev, V. M., Djondjorov, P. A. "Dynamic stability of viscoelastic pipes on elastic foundations of variable modulus", Journal of Sound and Vibration, 297(1-2), pp. 414-419, 2006. https://doi.org/10.1016/j.jsv.2006.03.025

[20] Ibrahim, R. A. "Overview of Mechanics of Pipes Conveying Fluids-Part I: Fundamental studies", Journal of Pressure Vessel Technology, 132(3), Article Number: 034001, 2010 https://doi.org/10.1115/1.4001271

[21] Naguleswaran, S., Williams, C. J. H. "Lateral Vibration of a Pipe Conveying a Fluid", Journal of Mechanical Engineering Science, 10(3), pp. 228-238, 1968. https://doi.org/10.1243/JMES JOUR 196801003502

[22] Thurman, A. L., Mote, C. D. "Nonlinear Oscillation of a Cylinder Containing Flowing Fluid", Journal of Manufacturing Science and Engineering, 91(4), pp. 1147-1155, 1969. https://doi.org/10.1115/1.3591763

[23] Païdoussis, M. P., Issid, N. T. "Dynamic stability of pipes conveying fluid", Journal of Sound and Vibration, 33(3), pp. 267-294, 1974. https://doi.org/10.1016/S0022-460X(74)80002-7

[24] Paidoussis, M. P., Laithier, B. E. "Dynamics of Timoshenko Beams Conveying Fluid", Journal of the Mechanical Engineering Science, 18(4), pp. 210-220, 1976. https://doi.org/10.1243/JMES JOUR 197601803402

[25] Païdoussis, M. P., Luu, T. P., Laithier, B. E. "Dynamics of finitelength tubular beams conveying fluid", Journal of Sound and Vibration, 106(2), pp. 311-331, 1986.

https://doi.org/10.1016/0022-460X(86)90321-4
[26] Nemat-Nasser, S., Prasad, S. N., Hermann, G. "Destabilizing Effect of Velocity-Dependent Forces in Nonconservative Continuous Systems", AIAA Journal, 4(7), pp. 1276-1280, 1966. https://doi.org/10.2514/3.3659

[27] Weaver, D. S., Unny, T. E. "On the Dynamic Stability of FluidConveying Pipes", Journal of Applied Mechanics, 40(1), pp. 48-52, 1973. https://doi.org/10.1115/1.3422971

[28] Païdoussis, M. P., Denise, J. P. "Flutter of thin cylindrical shells conveying fluid", Journal of Sound and Vibration, 20(1), pp. 9-26, 1972. https://doi.org/10.1016/0022-460X(72)90758-4

[29] Gupta, A. K. "Vibration of Tapered Beams", Journal of Structural Engineering, 111(1), pp. 19-36, 1985.

https://doi.org/10.1061/(ASCE)0733-9445(1985)111:1(19)

[30] Alshorbagy, A. E., Eltaher, M. A., Mahmoud, F. F. "Free vibration characteristics of a functionally graded beam by finite element method", Applied Mathematical Modelling, 35(1), pp. 412-425, 2011.

https://doi.org/10.1016/j.apm.2010.07.006

[31] Caruntu, D. "On Nonlinear Vibration of Nonuniform Beam with Rectangular Cross-Section and Parabolic Thickness Variation", In: Lavendelis, E., Zakrzhevsky, M. (eds.) IUTAM / IFToMM Symposium on Synthesis of Nonlinear Dynamical Systems. Solid Mechanics and its Applications, Springer, Dordrecht, Netherlands, 2000, pp. 109-118. https://doi.org/10.1007/978-94-011-4229-8_12

[32] Askarian, A. R., Abtahi, H., Firouz-Abadi, R. D. "On the static and dynamic stability of thin beam conveying fluid", Meccanica, 54(11), pp. 1847-1868, 2019. https://doi.org/10.1007/s11012-019-01055-7

[33] Zhao, Y., Huang, Y., Guo, M. "A novel approach for free vibration of axially functionally graded beams with non-uniform cross-section based on Chebyshev polynomials theory", Composite Structures, 168, pp. 277-284, 2017 https://doi.org/10.1016/j.compstruct.2017.02.012

[34] Datir, P., Lee, A. Y., Lamm, S. D., Han, H. C. "Effects of Geometric Variations on the Buckling of Arteries", International Journal of Applied Mechanics, 3(2), pp. 385-406, 2011. https://doi.org/10.1142/S1758825111001044

[35] Hosseini, M., Paparisabet, M. "The Effects of Blood Flow on Blood Vessel Buckling Embedded in Surrounding Soft Tissues", International Journal of Applied Mechanics, 8(5), Article Number: 1650065, 2016. https://doi.org/10.1142/S1758825116500654

[36] Benjamin, T. B. "Dynamics of a system of articulated pipes conveying fluid - I.Theory", Proceedings of the Royal Society A: Mathematical, Physical and Engineering Sciences, 261(1307), pp. 457-486, 1962 https://doi.org/10.1098/rspa.1961.0090

[37] Paidoussis, M. P. "Fluid-Structure Interactions: Slender Structures and Axial Flow", Academic Press, San Diego, CA, USA, 1998. 